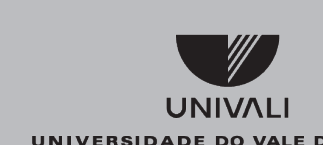

UNIVERSIDADE DO VALE DO ITAJAI

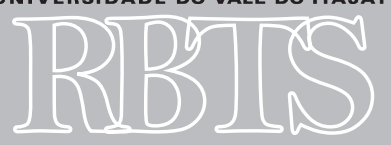

Revista Brasileira de Tecnologias Sociais

$1 \quad$ E-mail: $\quad$ camila.lanfredi@ hotmail.com.

2 E-mail: michelespereirao1@ gmail.com.

3 Psicóloga. Mestre em Psicologia pela Pontifícia Universidade Católica do Rio Grande do Sul. Professora da Universidade do Vale do Itajaí. E-mail: marciaoliveira3@terra.com.br.
Revista Brasileira de Teqhologias Sociais, v.3, n.2, 2016

doi: $10.1421 /$ /rbts.ty.n1.p73-87

\section{Adoção: um estudo sobre a perspectiva de pais adotivos}

\section{Adoption: a study of the perspective of adoptive parents}

\author{
Camila Aline LANFREDI ${ }^{1}$; Michele da Silva PEREIRA² $\&$ Márcia Aparecida \\ Miranda DE OLIVEIRA ${ }^{3}$
}

RESUMO: A presente pesquisa teve como objetivo analisar a vivência de pais adotantes frente à adoção de uma criança. Para isso realizou-se uma pesquisa de abordagem qualitativa com dois casais e duas mães, que efetuaram a adoção há no mínimo quatro anos, totalizando seis participantes como população para a pesquisa. Para a coleta de dados, utilizou-se uma ficha de identificação e uma entrevista semiestruturada do tipo exploratória. A análise de dados foi realizada pelo método de Análise de Conteúdo. Como resultado da pesquisa foi possível perceber que a realização da adoção tem como principal mobilizador a infertilidade de um dos cônjuges, aliada ao desejo intrínseco de se tornar pai/mãe. Em três dos quatro casos, percebeu-se que a construção do vínculo ocorreu de forma gradual. Referente ao relacionamento familiar, três dos casos referem que o mesmo é considerado pelos participantes como agradável e sem ocorrência de nenhum episódio perturbador ao convívio familiar. No entanto, um dos casos apresentou realidade distinta da relatada pelos demais, o que permite evidenciar que a dinâmica familiar constituída a partir da adoção apresenta diferentes contextos e complexidades.

Palavras-chave: Adoção; Família; Relacionamento Familiar.

ABSTRACT: This study analyzes the experience of adoptive parents in the adoption of a child. The study population for this qualitative study consisted of two couples and two mothers (six participants in all) who had been adopting for at least four years. For the data collection, we used an identification form and a semi-structured interview of the exploratory type. The data were submitted to Content Analysis. The results of the research showed that adopting a child is primarily motivated by the infertility of one of the spouses, along with the intrinsic desire to become a father or mother. In three out 
of the four cases, it was noted that the bond was formed gradually. Concerning family relationships, three of the cases indicated that the relationship was considered pleasant, without the occurrence of any episodes that disturbed the family life. However, one of the cases presented a different reality from that reported by others, demonstrating that the family dynamic surrounding the adopting presents different contexts and complexities.

Key words: Adoption; Family; Family relationship.

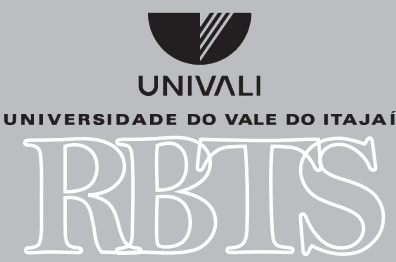

Revista Brasileira de Tecnologias Sociais 


\section{INTRODUÇÃO}

Com o avançar dos anos, pode-se evidenciar diversas mudanças que ocorreram no que se refere à família e à sua formação. Correspondendo a essa diversidade de constituições familiares, pode-se perceber que a adoção vem sendo realizada cada vez com mais frequência, estando presente no cotidiano da sociedade.

A adoção pode ser considerada em muitos casos como um ato de amor e carinho, que objetiva constituir e muitas vezes aumentar a família, buscando compartilhar sentimentos, experienciar e dividir as sensações advindas do estar junto do outro, dividindo todos os momentos e vivenciando o sentido de uma família.

Nos estudos Souza e Casanova (2012), evidencia-se que adotar é proporcionar à família adotante e ao filho por adoção a oportunidade de crescer e se constituir vivenciando todos os vínculos da filiação. Uma vez que essa criança é um filho que se decidiu ter, esta ideia deve ser congruente entre o casal, pois é imprescindível que os dois compartilhem o desejo da adoção para uma constituição familiar saudável.

Contudo, uma das problemáticas existentes referentes a essa temática se evidencia quando os pretendentes à adoção especificam as características físicas desejadas, buscando encontrá-las nos filhos por adoção, o que identificariam no filho biológico, bem como delimitando preferência por sexo e/ou faixa etária, o que ocasiona maiores empecilhos ao processo de adoção, fazendo com que o tempo de espera para a chegada do filho seja maior (LADVOCAT, 2008).

Destaca-se que, além da problemática criada a partir dessas exigências, existem também as questões envolvendo o processo jurídico da adoção, que muitas vezes é moroso devido a questões burocráticas do sistema judiciário.

Frente ao tema adoção, este estudo tem como objetivo geral analisar a vivência e os pais adotantes frente à adoção de uma criança; e como objetivos específicos, identificar questões mobilizadoras para realizar a adoção, descrever como se deu a construção de vínculo e o relacionamento familiar atual estabelecido. Com a realização deste estudo, busca-se propiciar à sociedade o acesso a essas informações e realidade muitas vezes desconhecida, como também uma possibilidade de desmistificar e desconstruir os preconceitos criados acerca da adoção. Também se pretende que, através destas informações, mais famílias possam sentir o desejo de realizar a adoção, para então se contribuir para o sentimento de realização dos pais adotantes e para o futuro das crianças e adolescentes que aguardam a oportunidade de vivenciar o sentido de família.

\section{REVISÃO BIBLIOGRÁFICA}

A história da adoção tem um percurso vasto no Brasil, sua concepção primeiramente foi associada a uma forma de caridade, conforme era pregado pela igreja. Era comum haver em casa pessoas filhas de terceiros, chamados "filho de criação" e, ainda, como uma possibilidade de mão de obra barata, na qual a pessoa adotada ganhava um lugar para morar junto com a família adotante e alimentação, e em troca era exigido que a mesma realizasse trabalhos para esta família (MAUX; DUTRA, 2010).

Com o avançar dos anos essa concepção foi se modificando, entretanto mitos e segredos continuaram norteando tal prática. Weber apud Maux e Dutra (2010) discorre que, no Brasil nos 
anos 80, a prática ilegal da adoção, conhecida como adoção à brasileira, caracterizada pelo ato de registar diretamente no cartório uma criança filha de outra pessoa como sendo sua, burlando as leis e sem passar pelos trâmites legais, constituía 90\% das adoções realizadas. Destacam-se pesquisas realizadas atualmente que afirmam que esses casos ainda existem, pois por mais que a lei proíba tal prática, a maioria dos brasileiros não sabem como se inicia o processo de adoção legal, bem como destacam a morosidade do processo jurídico como uma justificativa para tal prática.

A adoção aparece a primeira vez na legislação Brasileira em 1828, apresentando como objetivo solucionar o problema de casais que não podiam gerar filhos. Desde então, muitas mudanças ocorreram no âmbito legal, e no ano de 1990 com o Estatuto da Criança e do Adolescente (ECA), a prática da adoção foi regulamentada no Brasil, sendo modificada no ano de 2009, com a lei 12.010/09 chamada de "Nova lei da Adoção" (MAUX; DUTRA, 2010). Atualmente, o processo de adoção possui como intuito priorizar o interesse da criança, visando à solução que melhor atenda aos interesses da mesma, ou seja, um ambiente familiar saudável e uma motivação efetiva para a adoção (LADVOCAT, 2008; OTUKA; SCORSOLINI-COMIN; SANTOS, 2009).

A realização da adoção vem se apresentando cada vez com mais frequência no contexto social, expondo avanços quanto à sua compreensão e em questões jurídicas e sociais (LADVOCAT, 2008). No entanto, atualmente, ainda se percebe a existência de medos e preconceitos que envolvem os pretendentes à adoção e a família adotante. Entre os elementos que mais se apresentam, cita-se o medo de não ser amado pelo filho; medo de que a relação do filho por adoção com a família não seja de qualidade; preocupação com os sentimentos da família extensa para com o filho; e o medo por acreditar que crianças institucionalizadas tragam maus hábitos ao serem incluídas nos lares adotivos (OTUKA; SCORSOLINI-COMIN; SANTOS, 2009).

Otuka, Scorsolini-Comin e Santos (2009) realizaram uma revisão de literatura referente ao tema, investigando os motivos que levaram as pessoas a adotar, e afirmam que, na maior parte das vezes, a infertilidade de um dos cônjuges é o maior mobilizador para a adoção. No entanto, os motivos podem apresentar-se de forma variada, como nos casos em que os pais sempre pensaram em adotar; o desejo tardio de ter um filho; e pessoas que querem vivenciar o sentido de família, mas não possuem um parceiro. Encontram-se ainda outras mobilizações, como o desejo de aumentar a família e não desejar passar pela gestação; fazer parte do projeto de vida criado pelos pais; e ainda pessoas que fizeram cirurgia como laqueadura ou vasectomia e posteriormente decidiram ter filhos (SOUZA; CASANOVA, 2012).

Nos estudos de Rosa et al. (2016), observa-se que na história da família ocorreram diversas modificações ao que tange suas concepções e significados, o que varia de acordo com a época e cultura, e são definidas pelas autoras como adaptações às mudanças sociais. Deste modo, destaca-se a importância do cuidado em definir tal conceito e, ao defini-lo, é imprescindível que se compreendam o modo de representação e os componentes que compartilham a construção de "ser família hoje" (CHAVEIRO; SILVA, 2009).

Segundo Osório apud Pratta e Santos (2007), a família tem uma função importante na maturação e no desenvolvimento biopsicossocial dos sujeitos, proporcionando determinadas funções primordiais, salientando-se as funções biológicas, psicológicas e sociais. De acordo com a atualização teórica de Otuka, Scorsolini-Comin e Santos (2009), que aponta um resgate das ideias de Alfred Adler (1870-1937), é na relação entre irmãos que se inicia o desenvolvimento do contato social, preparando-o para o contato com a sociedade e, assim, possibilitando ao filho, e aqui especificado filho por adoção, um relacionamento diferenciado do disposto a eles pelos pais. 
Ao se discutir família e adoção, Verdi (2010) discorre que, para que ocorra uma efetiva construção de vínculo, impreterivelmente os integrantes da família devem assumir definitivamente seus papéis. Com a chegada de um novo membro para a família, os pais precisam se reorganizar quanto às relações familiares e oportunizar para a família momentos de conversa acerca da adoção, deixando claro como se deu, e informações quanto à família biológica, proporcionando à criança ou ao adolescente um espaço para questionamento, uma vez que em uma relação pautada na verdade e com papéis bem definidos a construção dos laços familiares será favorecida (VERDI, 2010; OTUKA; SCORSOLINI-COMIN; SANTOS, 2009).

\section{METODOLOGIA}

A presente pesquisa foi aprovada em primeira instância pelo Comitê de Ética na pesquisa com Seres Humanos da Universidade do Vale do Itajaí(UNIVALI) sobo número CAAE: 51194115 no dia 08/12/2015.

Trata-se de uma pesquisa de abordagem qualitativa, que possibilita um significante aproveitamento na área da Psicologia, visto que esta permite uma ampla exploração das informações coletadas contemplando a complexidade de tal pesquisa e permitindo o alcance dos objetivos. A pesquisa qualitativa tem como intuito a escolha adequada dos métodos e das teorias, a fim de coletar informações e analisá-las nas diferentes perspectivas sob as reflexões dos pesquisadores segundo o processo de produção do conhecimento (FLICK, 2009).

Referente aos participantes, entrou-se em contato com o Fórum de um município de Santa Catarina por meio da Assistente Social, quem entrou em contato com os pais adotantes e solicitou a autorização dos mesmos para fornecer seus contatos para as pesquisadoras. Após esta autorização, contatou-se os pais adotantes por meio de contato telefônico, apresentamos-lhes os objetivos da pesquisa e convidando-os para participarem dela.

A pesquisa teve o intuito de entrevistar separadamente seis casais, com idade superior a 18 anos, sendo esta a idade mínima para realizar a adoção, conforme previsto em lei e que adotaram uma criança há no mínimo seis meses, totalizando 12 participantes para a pesquisa. Foram considerados critérios de exclusão pessoas solteiras e casais que realizaram a adoção há menos de seis meses. No entanto, não se conseguiu realizar a entrevista com seis casais por ausência de disponibilidade de alguns indicados e dificuldade de conciliar o horário em que o esposo e a esposa estariam juntos para a entrevista. Desta forma, realizou-se a entrevista com dois casais, separadamente, e duas mães, os quais realizaram a adoção há quatro anos.

Todos os participantes são brasileiros, casados, possuem diferentes níveis de escolaridade, de profissão e idade ente 36 anos e 49 anos. Realizaram a adoção há pelo menos quatro anos e dois deles têm filhos biológicos. Os mobilizadores de adoção variam entre infertilidade e o desejo conjugal em adotar. No Quadro 01 está descrita a quantidade de filhos adotivos com a idade e o sexo de cada participante, bem como se já tinha ou não filhos biológicos, e a idade e o sexo destes. Os participantes estão descritos com a letra (F) para Feminino, e (M) para Masculino.

O local e horário para a realização da entrevista foram definidos durante o contato com cada participante, considerando a disponibilidade de ambas as partes, o espaço apropriado e livre de interrupções, mantendo-se e garantindo o sigilo. A duração da entrevista estimou-se em no máximo uma hora, sendo que todas as entrevistas foram gravadas e transcritas conforme autorização dos participantes. A entrevista foi realizada separadamente com cada um, mesmo nos 
casos dos casais, uma vez, que deste modo, um não influenciaria na opinião do outro, possibilitando o acesso a opiniões distintas sobre o mesmo contexto. Foram explicitados os objetivos da pesquisa dando ênfase ao Termo de Consentimento Livre e Esclarecido, bem como a ficha de identificação e posterior a assinatura com o aceite dos participantes.

Quadro 01: Ficha de identificação dos participantes.

\begin{tabular}{|c|c|c|c|c|c|c|c|c|}
\hline Participantes & Idade & $\begin{array}{c}\text { Escolarida- } \\
\text { de }\end{array}$ & Profissão & $\begin{array}{c}\text { Filho } \\
\text { Adoti- } \\
\text { vo }\end{array}$ & $\begin{array}{l}\text { Sexo/ } \\
\text { Idade }\end{array}$ & $\begin{array}{c}\text { Tem- } \\
\text { po de } \\
\text { ado- } \\
\text { ção }\end{array}$ & $\begin{array}{c}\text { Filhos } \\
\text { biológi- } \\
\text { cos }\end{array}$ & $\begin{array}{l}\text { Sexo/ } \\
\text { Idade }\end{array}$ \\
\hline $\begin{array}{l}\text { Casal } 1 \\
(M)\end{array}$ & 36 & $\begin{array}{l}\text { Ensino } \\
\text { médio }\end{array}$ & $\begin{array}{c}\text { Operador } \\
\text { de } \\
\text { máquina }\end{array}$ & 3 & & $\begin{array}{c}4 \\
\text { anos }\end{array}$ & Não & ---- \\
\hline $\begin{array}{l}\text { Casal } 1 \\
(F)\end{array}$ & 36 & $\begin{array}{c}\text { Superior } \\
\text { Incompleto }\end{array}$ & & 3 & & $\begin{array}{c}4 \\
\text { anos }\end{array}$ & Não & ----- \\
\hline $\begin{array}{l}\text { Casal } 2 \\
(M)\end{array}$ & 49 & $\begin{array}{l}\text { Superior } \\
\text { Completo }\end{array}$ & $\begin{array}{c}\text { Opera- } \\
\text { dor de } \\
\text { máquina }\end{array}$ & 1 & M- 4a. & $\begin{array}{c}13 \\
\text { anos }\end{array}$ & Sim & $M-6$ \\
\hline $\begin{array}{l}\text { Casal } 2 \\
(F)\end{array}$ & 39 & \begin{tabular}{|c|} 
Ensino \\
Médio \\
Incompleto \\
\end{tabular} & Do Lar & 1 & $\begin{array}{l}\text { M- } \\
14 a .\end{array}$ & $\begin{array}{c}13 \\
\text { anos }\end{array}$ & Sim & $M-6$ \\
\hline $\begin{array}{l}P 3 \\
(F)\end{array}$ & 44 & \begin{tabular}{|c|} 
Superior \\
Incompleto
\end{tabular} & & 1 & $F-4 a$ & $\begin{array}{c}4 \\
\text { anos }\end{array}$ & Não & ------ \\
\hline $\begin{array}{l}P 4 \\
(F)\end{array}$ & 39 & $\begin{array}{l}\text { Superior } \\
\text { Completo }\end{array}$ & Do Lar & 1 & $\begin{array}{l}\mathrm{F}- \\
12 \mathrm{a} .\end{array}$ & $\begin{array}{c}4 \\
\text { anos }\end{array}$ & Sim & $\begin{array}{l}F-23 \\
F-11\end{array}$ \\
\hline
\end{tabular}

Fonte: Pesquisadoras.

A análise de dados foi realizada por meio da técnica de Análise de Conteúdo, relacionando as informações coletadas nas entrevistas com o campo teórico. A análise de conteúdo se organiza em três fases: pré-análise (organização do material); exploração do material; e, por fim, o tratamento dos resultados, que visa elaborar uma exposição dos resultados de modo a serem válidos e significativos, momento este em que cabe aos pesquisadores a inferência e a interpretação das informações consideradas (BARDIN, 2009).

\section{RESULTADOS E DISCUSSÃO DOS DADOS}

\subsection{MOTIVAÇÃO PARA A ADOÇ̃̃O}

Os participantes dessa pesquisa, ao relatarem sobre suas motivações para realizar a adoção, evidenciaram a infertilidade de um dos cônjuges como o motivo principal para a adoção, no entanto, também apontam o desejo (sonho) de realizar a adoção e, ainda, em alguns casos, mencionou-se a adoção como uma prática comum na sua família e assim o motivo para tê-la realizado. Notou-se, ainda, que em cinco dos seis casos entrevistados a iniciativa partiu da mulher, 
gerando de início certo receio no companheiro, que por meio de diálogos resultou na aceitação e na preparação para o processo.

Ao que tange os motivos apontados por pais adotantes para realizar a adoção, encontrouse uma ampla diversidade de elementos, entre eles, poder escolher o sexo do filho, aumentar a família e realizar o desejo de ser pai/mãe. No entanto, os autores Otuka, Scorsolini-Comin e Santos (2009) realizaram um levantamento referente ao tema e evidenciaram que, predominantemente, o maior mobilizador para adoção é a infertilidade de um dos cônjuges. Nesta mesma perspectiva Ferreyra apud Souza e Silva (2013) aponta que o fato de casais estarem casados há alguns anos e não conseguirem ter filhos, assim como a ausência de filhos biológicos no lar, são elencados como motivadores para a adoção.

Entre as falas referentes à infertilidade, citam-se: (P3) “A gente resolveu adotar ela, adotar uma criança na verdade né, porque o meu marido, ele não podia mais ter filho (..)". Casal 2 (F) "Primeiramente eu e meu esposo tínhamos problema, não conseguíamos engravidar e como tem bastante criança para adoção, decidimos optar pela adoção”. Casal 2 (M) “(...) Primeiro que a fábrica não funcionava, já tava casado a uns dez anos mais e nós queria filho, mais nunca vinha (...) minha esposa sempre incentivava mais, eu concordei, quando vi que a coisa não dava certo (...)". Casal 1 (M) "Fiz todos os exames, minha esposa fez primeiro, tal, tranquilo pra ela, ai fez em mim, constatou que eu tinha varicocele (...) eu de início, não era muito a favor da ideia de adoção, aí minha esposa começou a conversar comigo".

Seguem relatos indicando o desejo de adotar, o Casal 1 (F) "Eu sempre tive esse desejo (...) minha mãe sempre teve esse desejo de adotar (...) e daí veio essa necessidade né, porque meu esposo tinha problema” e (P4) “(...) esse sempre foi um desejo nosso, não posso dizer que é porque a gente não podia ter filho, foi por vontade mesmo, porque a gente queria (...) a iniciativa foi minha, meu marido concordou, concordou tanto na adoção, quanto no perfil que colocamos (...)”.

Através das narrativas, pode-se considerar que, assim como descrito na literatura, apesar de terem ocorrido inúmeros avanços relacionados à temática, culturalmente a adoção ainda se apresenta fortemente atrelada aos valores atribuídos a ela desde o início da sua prática. Assim, diante dos relatos, evidenciou-se a predominância da infertilidade por parte de um dos cônjuges como motivo central dos participantes para realizarem a adoção. No entanto, além dessas questões, também foi apontada a existência de outros fatores mobilizadores, como o desejo existente de adotar em um dos pais e, ainda, a impossibilidade de gerar um filho, unido ao desejo antigo do cônjuge de realizar a adoção.

\subsection{FORMAÇÃO DE VÍNCULOS COM OS PAIS}

A prática da adoção modificou a compreensão sobre a família, tornando evidente o novo entendimento que se pode ter pela família moderna e sua composição fundamentada na afetividade, uma vez que esta nasce na convivência entre indivíduos e a reciprocidade de emoções. Conforme Oliveira (2002 apud SIMÕES, 2007), a afetividade pode ser definida pelo respeito que cada um tem por si e por todos os membros, com o objetivo de que a família seja respeitada em sua honorabilidade e dignidade diante do âmbito social, sendo essa uma das maiores características da família contemporânea.

Desta forma, referente ao primeiro contato dos pais com a criança, destacam-se as falas: Casal 1 (M) "A gente chegou lá, a assistente social mostrou a foto deles, nossa ali já bateu aquela coisa, 
nossa já vi a pequenininha, já vi os outros dois (..) aí fomos lá, já tivemos o contato, e, foi uma coisa assim, inexplicável (...) peguei ela no colo, parou de chorar, aí já começou a adaptação (...)». Casal 1 (F) “(...) Eu fiquei muito feliz assim, porque fazia tempo que eu queria ter meus filhos, então pra mim foi assim muito bom (...) foi muito bom o contato com eles no início, e eles conosco também (...)". Casal 2 (F) "Foi amor à primeira vista (...) ele levantou, era verão, dia 23 de janeiro, ele veio de cueca e com aquelas coxas, coxudo ele era, e veio direto no meu marido, direto assim, se encostando, se encostando e pedindo colo (...)”. (P4) “(...) Então fomos até a cidade e lá a gente foi no abrigo conhecer ela, passamos o dia com ela no abrigo, a noite a gente pegou ela e levou ela pra passear, comer pizza, ela dormiu com a gente no hotel e no outro dia a gente voltou, mas assim, foi uma sensação bem diferente, aquela espera (...)”.

Desta forma, pode-se considerar que, em todos os casos, o primeiro contato dos pais com a/as criança(s) resultou em imensa alegria, satisfação, êxtase e amor. Observou-se ainda que, em alguns casos, os pais foram previamente preparados para aceitar a antiga realidade da criança, sabendo que esta poderia influenciar de maneira positiva ou negativa na formação do vínculo, o que teve resultado positivo, pois os pais já tinham embasamento para lidar com algumas situações vivenciadas durante o período de adaptação da criança.

Sobre a formação de vínculo, foi perceptível falas como: Casal 2 (M) “(...) Ele se apegou bastante em mim, a gente tava querendo ir embora, ele chorou, aí tive que pegar colocar ele no carro, dar uma voltinha e trazer de volta pra vó e assim foi o primeiro dia. (...)". Casal 2 (F) "A adaptação, eu tinha medo, eu tinha 26 anos, sempre quis uma criança, mas eu tinha medo que não ia dar jeito sabe (...) foi normal, como se ele estivesse na casa dele, no quarto dele, ele dormia muito bem (...)". Casal 1 (M) "No caso dos mais velhos foi um pouco tumultuado, teve os momentos que oscilava entre satisfação, alegria, mas teve aquele momento tumultuado que você tinha que ir na escola resolver assunto de comportamento. Agora a mais nova, foi supertranquilo, ela tinha um ano e dois meses, então meu, o dia em que ela me chamou de pai pela primeira vez (...) eu me desmanchei”. Casal 1 (F) “(..) Os dois, eles não reconheciam a neném como irmã deles (...) nessa parte ali a gente teve que trabalhar muito, então assim, a gente tinha que fica em cima porque ela queria mata a neném, muitas vezes ela mesmo queria se matar, então tinha que fica em cima (...)”.

Percebeu-se que em três dos casos a aceitação e a formação do vínculo ocorreram sem intercorrências aparentes e de acordo com o esperado pelos pais adotantes. Porém o Casal 1 (M) e Casal 1 (F) referiram que as crianças apresentaram resistência para com os pais adotantes e a irmã caçula, recusando-se a aceitá-los e não se sentindo como integrante da família. Os participantes relataram que houve situações em que uma das irmãs "tentou matar a irmã mais nova, e ela mesma tentou o suicídio".

\subsection{VÍNCULO COM OS IRMÃOS}

Outro aspecto importante é o funcionamento do relacionamento entre os irmãos. Sabese que a chegada de uma criança na família, sendo ela adotiva ou não, é um processo que exige uma reorganização familiar, nesse aspecto, a criança adotiva criada junto do filho biológico de uma mesma família pode resultar em medos e emoções ambivalentes. Muitas vezes os pais se preocupam em não criar diferenças entre um e outro, com o intuito de evitar que o filho adotivo se sinta excluído (SANTOS et al., 2003).

Já na relação entre irmãos pode surgir inveja, rivalidades, ressentimentos e segredos, bem como apoio e ajuda, haja vista que os irmãos irão funcionar um para o outro como uma fonte de aprendizagem e identificação recíprocas. É importante destacar também que, na medida em que 
envelhecem juntos, o relacionamento amadurece, uma vez que o vínculo de irmão se transforma em vínculo entre irmãos (CÚNEO et al. apud OTUKA; SCORSOLINI-COMI; SANTOS, 2009).

Neste caso, pode se destacar as situações descritas pelos pais: (P4) “(...) Foi muito tranquila. No começo houve umas situações em que ela apresentava alguma coisa pelo o que aconteceu com ela. (...) ai eu conversei com ela. (...) "Casal 2 (F) "É eu diria que é normal, nada que possa chamar a atenção, relacionamento assim com o meu e dos meus irmãos, não tem nada de especial (...)". Casal 1 (F) "Essa resistência deles ali que não aceitavam a pequena como irmã e a té hoje assim (..) sempre brigaram muito (..) então sempre tivemos que trabalhar muito isso (...)”.

Entre as quatro famílias entrevistadas, somente em uma delas o filho adotivo não tem irmãos (P3), sendo que nas demais um deles tem um irmão (Casal 2), outro tem duas irmãs (P4), e a outra família (Casal 1) é constituída com três filhos por adoção, sendo que os três são irmãos biológicos.

Frente às narrativas, notaram-se duas situações distintas no que diz respeito à formação de vínculo com os irmãos. De um lado deu-se de forma tranquila, através de conversas com os irmãos e a criança adotiva, com intuito de explicar a reestruturação que a família teria a partir daquele momento, a importância do cuidado e do apoio de um para com o outro. No entanto, o casal denominado 1 referenciou outra experiência, houve dificuldade na reaproximação entre os três irmãos e resistência das crianças adotadas em aceitar a nova família.

\subsection{VÍNCULO COM A FAMÍLIA EXTENSA}

Assim como quando ocorre o nascimento de uma criança, toda a família precisa de um tempo de ajustamento à nova situação. A chegada de uma criança adotiva exige o mesmo movimento. Desta forma, ao introduzir uma criança em um novo ambiente familiar, acontece a formação de uma nova rede de relacionamentos, sendo indispensável que seja fornecido à criança um ambiente de amor, atenção, carinho, comprometimento e respeito quanto à sua história de vida (MARTINS apud SANTOS et al., 2003).

Referente ao vínculo do filho por adoção com a família extensa, destacam-se as seguintes falas: Casal 1 (F) "Foi muito bom, muito bom mesmo (..) minha mãe tem eles assim como netos mesmo (...) fizeram uma recepção maravilhosa lá pra eles. (...)".(P3) "Ela foi muito bem recebida por todos, e assim tanto da minha família quanto da família do meu marido (..) foi bem tranquilo (...)”. (P4) "O meu pai no começo foi contra, quando a gente pegou ela (...) e com o resto da família foi bem tranquilo, no começo ela era bem envergonhada (...) mas depois ela se soltou. Casal 2 (F) "Foi muito bom, ele foi muito desejado, a família via a gente sofrendo muito, que queria muito um filho (...) “.

A família extensa revelou-se como uma rede de relacionamentos de grande importância no processo de adoção, fornecendo o apoio emocional necessário no decorrer do mesmo. Destacase também que houve uma grande expectativa e espera pela chegada da criança no sistema familiar. No entanto se deve ressaltar um caso em que o pai da mãe adotante se mostrou resistente ao ato, alegando que a mesma estava procurando problemas para sua vida; porém, após alguns meses de convívio com a criança, criou-se uma boa relação entre eles.

\subsection{RELACIONAMENTO FAMILIAR ATUAL}

Conforme Cerveny (2006), todo o indivíduo em sua rede de relacionamentos desenvolve um entendimento diferente do significado de família. Memórias e histórias criadas entre os 
membros da mesma, por meio de palavras, atitudes, gestos ou até mesmo através do silêncio, auxiliam para a construção de uma rede de crenças partilhadas a respeito da família de cada um, sustentada ou reelaborada em diferentes fases da vida.

\subsection{RELACIONAMENTO ATUAL COM OS PAIS}

No aspecto psicológico, a adoção se baseia na ideia de que a criança, ao se integrar a uma nova família, poderá reconstruir sua identidade através da formação de um relacionamento adequado com as novas figuras paterna e materna, de forma que os mesmos possam proporcionar à criança um lugar seguro para o seu desenvolvimento, oferecendo o contentamento de suas necessidades principais, além de uma elaboração dos traumas estabelecidos pela quebra dos primeiros laços afetivos (PEREIRA; SANTOS apud SANTOS et al., 2003).

Nesta perspectiva, destacam-se as falas dos seguintes participantes: Casal 1 (M) "Olha um tempo atrás era bom, bom pra quase chegando em ótimo, mas só que por causa dessas comunicações, o filho descobre de repente a mãe, então tá um tumulto intenso lá em casa, (...) só tô segurando mesmo a situação, por força de Deus, porque há um esgotamento intenso". Casal 1 (F) "Hoje tá bem difícil principalmente agora que eles descobriram a mãe, todos aqueles parentes, (..) ai não quer obedecer mais, (...) e fala sempre, ai eu vou embora, (...), ele culpa a gente, por nos ter tirado ele de lá (..)”. Casal 2 (F) “(...) o relacionamento hoje é maravilhoso, ele é meu tudo e divide tudo comigo (...) Acho que se fosse meu biológico, não seria tão agarrado comigo, não seria tão ligado, quanto é assim. É um amor, não sei”. (P4) “(...) hoje ela ainda é muito apegada a ele (pai). Claro que comigo também, só que assim, ela se identificou muito com ele, no começo já, era uma coisa que a gente tinha muito medo, porque a gente já foi preparado, sabendo o que tinha acontecido”.

Através do exposto foi possível observar realidades distintas. Com exceção de um caso, as crianças adotadas atualmente mantêm uma boa relação com os pais, destacam-se palavras como comum, normal, natural, utilizadas para descrever esse relacionamento. No entanto, houve o relato de um casal de pais (Casal 01) que adotou três irmãos, no entanto, vem enfrentando dificuldades na relação com os filhos, fato que ganhou força após o filho mais velho ter encontrado a mãe biológica em uma rede social e vir mantendo contato com ela desde então, apresentando episódios de agressão e irritabilidade em casa e contra as irmãs. Nesse caso os pais afirmam que, como enfrentamento da situação, estão buscando ajuda psicológica, além de conversar com os filhos e manter a fé.

\subsection{RELACIONAMENTO ATUAL COM OS IRMÃOS}

A chegada do irmão pode representar a presença de um “estranho”, cuja integração no ambiente familiar altera o equilíbrio estabelecido. Através da chegada do irmão é iniciado o entendimento de mudança, de igualdade e semelhança, bem como os primeiros entendimentos a respeito de lei e justiça. A partir da chegada do segundo filho, será necessário fazer uso de partilhas, julgamentos e negociações. Desta forma, o filho mais velho precisará reorganizar seu lugar e seu jeito de pensar devido à presença do novo irmão, exigindo assim mais de si (KLEIN apud GOLDSMID; FÉRES-CARNEIRO, 2007). Vale destacar também que vários aspectos, tais como a diferença de idade, gênero, influências parentais e comportamento infantil no dia a dia, poderão dificultar ou facilitar o relacionamento entre os irmãos (GOLDSMID; FÉRESCARNEIRO, 2007). 
Nesta perspectiva, evidenciaram-se tais falas: Casal 1 (F) "Ela fala que não gosta do irmão, eu odeio você (...) o menino bate muito nas meninas, bate mesmo, ele é muito revoltado (...) as meninas são muito abertas, quando querem um abraço vem e pedem (...) o menino não, a gente vai até ele e ele não quer (..) ele tem vergonha de nos (...) então é essa parte deles ali que a gente sempre tá trabalhando”. Casal 2 (M) "É eu diria que é normal, nada que possa chamar a atenção (...) relacionamento assim com o meu e dos meus irmãos, não tem nada de especial (...)”. Casal 2 (F) “(...) Ele cuida, se pedir pra ele dar banho nele, ele dá banho, é o irmão dele (...) um relacionamento de irmão mesmo”. (P4) “(...) Então elas se dão muito bem, tem às vezes as brigas como todo irmão tem, porque a gente tem que estranhar quando eles não brigam, porque aí tem algo errado".

Percebe-se, portanto, que mesmo nos casos em que ocorreram conflitos iniciais entre os filhos biológicos e a criança adotiva, o vínculo atual parece se manter adequado. No entanto, destaca-se novamente a situação do casal 1, em que os irmãos, mesmo sendo biológicos, não conseguem se relacionar adequadamente, o que acaba por gerar conflitos dentro da família, como é salientado pelos pais.

\subsection{RELACIONAMENTO ATUAL COM A FAMÍLIA EXTENSA}

A família extensa ou parentalidade pode ser vista como uma rede de relacionamentos de grande influência no ajustamento psicológico e afetivo do indivíduo e em suas relações familiares, mas também deve se levar em conta questões mais particulares, como problemas envolvendo família e escola, depressão, entre outros (SCHWARTZ; THIGPEN; MONTGOMERY apud CERVENY, 2006). Desta forma é possível perceber a importância do bom relacionamento também com os demais familiares para o desenvolvimento da criança.

Frente ao relacionamento com os demais familiares, destacam-se as seguintes falas: Casal 1 (M) "Hoje tá tudo tranquilo também, tanto é que nesse momento tumultuado que a gente tá vivendo, a gente não passa para eles (família extensa), pra não quebrar ne". Casal 1 (F) "Agora depois que eles conheceram a mãe, eu percebi assim que já tem tia que eles já não chamam de tia (...) aí parece que quebrou, essa não é minha família, minha família é aquela (...)". Casal 2 (M) "Hoje é a mesma coisa, todo mundo gosta dele, minha mãe principalmente, gosta muito dele (...) todo mundo trata ele como se tivesse nascido aqui e nada tivesse acontecido (...)”. (P3) “(...) assim a gente já não convive muito um na casa do outro, mas quando eles vão lá em casa é bem tranquilo com ela sabe, (...)”. (P4) “(...) hoje é tranquilo também, a gente chega lá e ela corre para beija os tios, sai com eles, bem tranquilo".

Com relação à família extensa, percebe-se que o relacionamento atual apresenta indícios de bom relacionamento, incluindo laços afetivos e ambiente familiar favorável para o desenvolvimento das crianças, uma vez que os relatos afirmam efetividade na inclusão da criança com a família extensa. Com exceção do Casal 1, que relatou perceber que, após o contato com a mãe biológica, os filhos deixaram de dirigir-se aos familiares da maneira como faziam antes. No entanto, não houve nenhum outro relato de casos atuais sobre conflitos com a família extensa, referente aos respectivos casos de adoção, o que de fato é algo importante para o funcionamento familiar.

3.9 Concepção de adoção segundo a perspectiva de pais adotantes

A adoção em sua amplitude envolve muitos aspectos, jurídicos, sociais e afetivos, sendo assim, deve ser significativamente pensada e analisada por todos os envolvidos, considerando a plena certeza da tomada de decisão (REPPOLD; HUTZ apud SOUZA; SILVA, 2013). Maux e 
Dutra (2010) apontam, por meio de suas experiências em um juizado da infância e da juventude junto a famílias adotantes, ter percebido que, embora a adoção seja vivenciada de forma singular por cada família, existem relações que aparecem com bastante frequência, como: relação adoção e caridade, adoção e infertilidade, mitos e medos relacionados com a revelação da adoção ao filho.

Percebe-se a necessidade de conhecer a concepção de adoção segundo os pais que a vivenciaram e descrever seus pensamentos a partir disso, deste modo, o Casal 1 (M) aponta "Olha, eu penso a adoção, bebê, tranquilo, supertranquilo, já acima de, acho que acima de sete anos, já precisa se pensar bem mais, se precisa pensar como tá teu emocional, precisa se pensar como tá o teu convívio, você na questão do teu casamento, como que esta você e tua esposa, se tá uma coisa solida, firme (...)”. E Casal 1 (F) "Eu ainda continuo achando que é um ato muito lindo, e é um ato heroico e corajoso, (..) principalmente uma idade tardia tem que ter muita coragem e perseverança porque se não, não vai até o fim (...) Mas eu continuo acreditando na adoção (...)”.

Os pais que foram denominados Casal 1 chamam a atenção para a questão da adoção tardia, no entanto apontam uma idade superior à idade definida judicialmente para tal categoria, uma vez que, segundo Oliveira, Magalhães e Pedroso (2013), a adoção tardia é caracterizada pela adoção de criança com idade superior a dois anos.

Esses mesmos pais acreditam que a adoção tardia a partir de sete anos apresenta maiores complexidades, uma vez que nesta modalidade de adoção se apresentam maiores dificuldades na adaptação da criança com os pais adotantes, a construção das regras, as mudanças na rotina do casal e a relação de afeto, sendo necessário o uso de estratégias para facilitar a vinculação afetiva com essas crianças (COSTA; ROSSETTI-FERREIRA apud OLIVEIRA; MAGALHÃES; PEDROSO, 2013).

Os autores Costa e Rossetti-Ferreira apud Oliveira, Magalhães e Pedroso (2013) apontam que a adoção precoce, sendo esta com idade inferior a dois anos, apresenta uma melhor adaptação dos envolvidos, fato que se pode evidenciar na fala da participante (P3) "Ela era um bebe, então, às vezes eu esqueço que ela é adotiva, eu digo assim, ela é tão minha, ela é tão eu, que eu não vejo diferença (...) eu me sinto gratificada, sabe, eu até tinha manifestado interesse em adotar de novo, mas como demora muito, eu acho que não adianta (...)”.

Já o participante (P4) refere: “(...) Acho que adoção é muito lindo, se eu pudesse adotaria mais. Não adoto porque tenho três meninas e elas me deixam louca, mas se pudesse adotaria mais (...)”. Casal $2(\mathbf{F})$ "Eu acho muito bom, porque tem tanta criança precisando de carinho e tem tantos pais que tem carinho pra dar, então eu sou muito a favor (...)". O Casal 1 (F) refere a adoção como um ato de amor, de fazer o bem para o outro, fato mencionado pelos autores Maux e Dutra (2010) como um pensamento construído devido à forma como a temática ficou conhecida na cultura brasileira, e que se perpetua até os dias atuais.

Já o Casal 2 (M) descreve a adoção como uma possibilidade para casais que não possuem e que desejam ter filhos: “(...) Eu aconselho, quem quer se inscreve que é uma saída né, (...) O caminho mais simples, porém, mais longo. É o caminho que eu aconselho e dá tempo pra se preparar também”. Conforme aponta Maux e Dutra (2010), a adoção e a infertilidade são uma das principais ligações realizadas por pais adotantes.

Frente ao analisado, pode-se perceber posicionamentos de pais que adotaram crianças maiores e pais que adotaram bebês. Os pais que adotaram crianças maiores apontam que têm 
enfrentado dificuldades no processo de educação, os quais atribuem ao fato de ter adotado uma das crianças com idade mais avançada, já os pais que adotaram bebês afirmam sentir uma sensação de pertencimento para com o filho, como se esquecesse que o mesmo é adotado.

Além dessas questões, destaca-se a narrativa de uma participante ( $\mathrm{P} 4$ ) que refere a morosidade do processo como o motivo para o qual não realiza a adoção novamente. Evidenciando que a adoção ainda está bastante atrelada ao desejo de fazer o bem para crianças carentes e como uma opção para casais que não possuem condições de ter seus filhos biológicos, fato este bastante apontado na literatura, sendo que se busca, através dos novos movimentos da "adoção moderna", desconstruir essas concepções, buscando atrelar o significado de adoção ao fato de encontrar uma família para a criança/adolescente e não o oposto.

\section{CONSIDERAÇÕES FINAIS}

A adoção está presente na cultura brasileira desde a antiguidade, sendo regida por diversas concepções de acordo com a época vigente. Inicialmente não possuía nenhum amparo jurídico, era realizada sobre uma prática que posteriormente foi denominada "adoção à brasileira", ou seja, de forma ilegal. Com o avançar dos anos a adoção adquiriu o respaldo jurídico que ampara sua realização, passando a se apresentar cada vez com mais frequência na sociedade e conquistando um espaço em ascensão na literatura.

Na presente pesquisa, de acordo com as narrativas, foi possível perceber que a realização da adoção tem como principal mobilizador a infertilidade aliada ao desejo intrínseco de se tornar pai/mãe, no entanto se apresentaram outros fatores, como no caso de casais que, mesmo possuindo filhos biológicos, têm o interesse em realizar a adoção, alegando ser um desejo antigo.

Evidenciou-se em três dos casos que a construção dos vínculos ocorreu de forma considerada natural, uma vez que, desde o primeiro contato, a afetividade entre os envolvidos foi sendo construída gradativamente. Porém se aponta que, referente ao denominado Casal 1, o processo de construção de vínculo inicialmente ocorreu de forma harmoniosa; entretanto, no decorrer do convívio familiar, apresentaram-se questões conflituosas entre os irmãos mais velhos, como também a ausência de reconhecimento por parte dos filhos para com a família adotante como sua.

No que tange o relacionamento familiar, percebeu-se em três dos casos que o relacionamento atual é considerado pelos participantes como agradável e sem ocorrência de nenhum episódio perturbador ao convívio familiar, o que está relacionado com a efetividade ocorrida na construção de vínculo. No entanto, destaca-se também a situação do Casal 1 que, como reflexo da dificuldade na formação de vínculo, refere atualmente situações conflitantes em seu cotidiano, descrevendo o próprio relacionamento como difícil e provocador de esgotamento.

Frente à temática abordada nesse artigo, conclui-se que, independente dos motivos mobilizadores e da constituição familiar, ou seja, se possui filhos biológicos ou não, e a quantidade de filhos, em três das famílias participantes, a adoção e a inserção da criança na família foram compreendidas como de forma tranquila e adequada para o desenvolvimento dos envolvidos.

Salientando ainda a exceção do Casal 1, em que se percebeu que não foi possível identificar aspectos de um relacionamento harmonioso na família, uma vez que mesmo a adoção tendo ocorrido há quatro anos, relata-se que os filhos adotivos não apresentaram indícios de pertencimento à 
família e adequação ao ambiente, sendo que os filhos mais velhos direcionam a culpabilização de não estarem mais no abrigo aos pais adotantes e trazerem à tona o interesse em voltar para a família biológica.

Deste modo, pode-se afirmar que os objetivos dessa pesquisa foram alcançados. No entanto se considera de grande complexidade definir o que é a adoção, uma vez que esta se constitui a partir de uma gama de fatores que está relacionada à complexidade do relacionamento familiar e atrelada a questões específicas a partir da realização da prática e da concepção que a adoção traz consigo.

\section{REFERÊNCIAS}

BARDIN, L. Análise de Conteúdo. Lisboa: Edições 70, 2009.

CHAVES, U. H. Família e Parentalidade. In: CERVEny, C. M. de O. (Org.). Família e... São Paulo: Casa do Psicólogo, 2006.

CHAVEIRO, E. F.; SILVA, M. C. da. Demografia e Família: as Transformações da Família no século XXI. Boletim Goiano de Geografia, Goiânia, v. 29, n. 2, p. 171-183, jul./dez. 2009.

FLICK, U. Introdução à Pesquisa Qualitativa. 3. ed. Porto Alegre: Artemed, 2009.

GOLDSMID, R.; FÉRES-CARNEIRO, T. A função fraterna e as vicissitudes de ter e ser um irmão. Psicologia em Revista, Belo Horizonte, v. 13, n. 2, p.293-308, 05 dez. 2007.

LADVOCAT, C. Mitos e Segredos Sobre a Origem da Criança na Família Adotiva. Rio de Janeiro: Booklink, 2008.

MAUX, A. A. B.; DUTRA, E. A Adoção no Brasil: Algumas Reflexões. Estudos e Pesquisas em Psicologia, Rio de Janeiro, v. 10, n.2, p. 356-372, 2010.

OLIVEIRA, M. L. S. de; MAGAlHÃES, C. M. C.; PEDROSO, J. da S. Família Adotante: Estudo de caso de Adoção Tardia. Revista Brasileira de História e Ciências Sociais, São Leopoldo, v. 5, n. 9, p. 22-36, 2013.

OTUKA, L. K.; SCORSOLINI-COMIN, F.; SANTOS, M. A. dos. A Configuração dos Vínculos na Adoção: Uma atualização no contexto latino-americano. Revista Brasileira de Crescimento e Desenvolvimento Humano, São Paulo, v. 3, n. 19, p.475-486, 2009.

PRATTA, E. M. M.; SANTOS, M. A. dos. Família e Adolescência: a Influência do Contexto Familiar no Desenvolvimento Psicológico de seus membros. Psicologia em Estudo, Maringá, v.12, n.2, p.247-256, maio/ago. 2007.

ROSA, J. M.; MELO, A. K.; BORIS, G. D. J. B.; SANTOS, M. A. dos. A Construção dos Papéis Parentais em Casais Homoafetivos Adotantes. Psicologia: ciência e profissão, Brasília, v. 36, n.1, p.210-223, jan./ mar. 2016.

SANTOS, M. A. dos; RASPANTINI, R. L.; SILVA, L. A. M. da; ESCRIVÃO, M. V. Dos laços de sangue aos laços de ternura: o processo de construção da parentalidade nos pais adotivos. PSIC - Revista de Psicologia da Vetor Editora, São Paulo, v. 4, n. 1, p.14-21, 10 out. 2003.

SIMÕES, T. F. V. A Família Afetiva: O Afeto como Formador de Família. [S.I.]. Disponível em: <http:// www3.promovebh.com.br/revistapensar/art/a 19.pdf>. Acesso em: 02 mar. 2017. 
SOUZA, H. P. de; CASANOVA, R. P. de S. Adoção: O Amor faz o Mundo Girar mais Rápido. Curitiba: Juruá, 2012.

SOUZA, J. G. de; SILVA, V. R. de O. Motivação: Adoção na Família. [S.I.]. Disponível em: <http:// docplayer.com.br/6472651-Motivacao-adocao-na-familia-jessica-galindo-de-souza-1-rgm-08732 1. html>. Acesso em: 02 mar. 2017.

VERDI, M. T. Trabalhando os Vínculos Familiares: a Questão da Adoção. Vínculo, São Paulo, v. 7, n. 1, p. 23-32, jun. 2010. 